\title{
Pengelolaan Rehabilitasi Lahan Kritis berdasarkan Partisipasi Masyarakat di DAS Randangan Kabupaten Pohuwato
}

\section{Critical Land Rehabilitation Management Based on Community Participation in Randangan Watershed, Pohuwato District}

\author{
Dewa Oka Suparwata $^{1 *}$ \\ ${ }^{1}$ Program Studi Agribisnis, Fakultas Ilmu-Ilmu Pertanian, Universitas Muhammadiyah \\ Gorontalo \\ J1. Prof. Dr. H. Mansoer Pateda, Desa Pentadio Timur, Kec. Telaga Biru, Kab. Gorontalo \\ ${ }^{*}$ Tel./Faks. +62-435-881135/+62-435-881136 \\ E-mail: suparwata_do@umgo.ac.id
}

\begin{abstract}
Tectical steps that can be done for reconditioning critical land is through land rehabilitation activity. The fundamental key to a successfull rehabilitation of critical land is community participation. The purpose of this research is to analyze the level of community participation in managing critical land rehabilitation. This research was conducted in Randangan Watershed Pohuwato District from April 2017 to July 2017. The design of the research is survey. The samples of research was 60 respondent that were taken through proportional random sampling. The data were analyzed descriptively will low, moderate and high scale. The resul vevealed that in the level of planning, the community participation is low in terms of determining the rehabilitation site $(65 \%)$ and determining the type of plant $(70 \%)$. In implementation is considered as moderate in seed maintenance $(53.3 \%)$ and planting seed $(58.3 \%)$ but low on determining the patern and planting distance $(55 \%)$ and planting cultivation $(56.6 \%)$. The evaluation stage is considered low is terms of planting monitoring (66.7\%). This indicates the low level of awareness from the community therefore a concrete act is reeded in critical land management.
\end{abstract}

Keywords: rehabilitation, Critical Land, Community Participation

\begin{abstract}
ABSTRAK
Langkah tatis yang dapat dilakukan dalam merekondisi kembali lahan-lahan pertanian yang telah kritis adalah dengan kegiatan rehabilitasi lahan. Hal mendasar yang menjadi kunci sukses rehabilitasi lahan kritis adalah adanya partisipasi masyarakat. Tujuan penelitian ini untuk mengkaji tingkat partisipasi masyarakat dalam pengelolaan rehabilitasi lahan kritis. Penelitian ini dilakukan di DAS Randangan Kabupaten Pohuwato, pada Bulan April sampai Juli 2017. Memilih survei sebagai desain penelitian. Besar sampel penelitian berjumlah 60 responden, yang ditentukan secara proportional random sampling. Data dianalisis dengan skala rendah, sedang dan tinggi, serta analisis deskriptif. Hasil penelitian menunjukkan bahwa pada perencanaan tingkat partisipasi masyarakat rendah pada penentuan lokasi rehabilitasi (65\%), dan penentuan jenis tanaman (70\%). Pada pelaksanaan tergolong sedang pada pemeliharaan bibit $(53.3 \%)$, penanaman bibit $(58.3 \%)$, tetapi rendah pada penentuan pola dan jarak tanam $(55 \%)$, dan penyulaman tanaman $(56.6 \%)$. Tahap evaluasi tergolong rendah untuk melakukan monitoring pertanaman $(66.7 \%)$. Hal ini mengindikasikan bahwa masih minimnya tingkat kesadaran masyarakat, olehnya dibutuhkan gerakan konkrit untuk pengelolaan lahan kritis.
\end{abstract}

Editor: Siti Herlinda et. al.

ISBN : 978-979-587-748-6 
Kata Kunci: rehabilitasi, Lahan Kritis, Partisipasi Masyaraka

\section{PENDAHULUAN}

Wajah pertanian di Indonesia saat ini terlihat usang dan terpruk, apalagi dalam pengelolaan lahan-lahan pertanian. Pertanyaan yang mendasar sering dilontarkan dalam pengelolaan lahan adalah "Bagaimana kesuburan tanah kita saat ini dan ke depan?", "Apakah kita akan mewariskan tanah yang sehat dan subur kepada anak cucu kita?", "Masihkah pertanian menjadi sektor andalan dalam menyerap tenaga kerja, peningkatan pendapatan masyarakat Indonesia?", dan "Apakah Indonesia masih layak dikatakan sebagai negara Agraris?". Semua pertanyaan ini menjadi cambuk kepada wajah pertanian di Indonesia saat ini yang semakin terkebelakang, dengan carut marutnya sebagian sub sektor di pertanian. Sehingga berimbas pada peningkatan kemiskinan di pedesaan. Dahlan (2012), kemiskinan pada dasarnya merupakan fenomena pedesaan, lebih khusus lagi pertanian. Arifin (2013), petani hidup miskin berawal dari tidak memiliki kemampuan (intitlement), tidak memiliki kebebasan (freedom) untuk melakukan sesuatu bagi keluarganya. Sehingga pemerintah saat ini harus memberikan perhatian serius terhadap pembangunan pertanian melalui program revitaslisasi pertanian (Nuhung, 2012). Setidaknya ada beberapa hal yang dilakukan untuk menurunkan kemiskinan di pedesaan, yaitu: (i) sumberdaya manusia petani, (ii) asset (lahan dan teknologi), (iii) akses terhadap fasilitas social, (iv) akses terhadap informasi, (v) aktivitas ekonomi pertanian, dan (vi) aktivitas non-ekonomi pertanian (Arsyad, 2012). Disamping itu, rendahnya hasil-hasil pertanian menjadi faktor utama rendahnya pendapatan petani. Rendahnya hasil pertanian yang diperoleh petani salah satunya disebabkan oleh rendahnya daya dukung lahan pertanian untuk dapat mensuplai hara/nutrisi kepada tanaman. Dalam kondisi yang secara terus menurus, sehingga tanaman tidak akan tumbuh dengan baik karena kahat hara. Lambat laun akan timbul pula masalah klasik dari petani bahwa rasa enggan untuk melakukan budidaya kembali, karena lahan mereka tidak produktif lagi.

Kondisi lahan yang tidak produktif ini bila diterlantarkan dan tanpa perlakuan perbaikan maka akan dapat membentuk lahan menjadi kritis. Lahan yang kritis terjadi karena akibat dari penggunaan lahan yang tidak menerapkan teknik-teknik konservasi atau pengawetan tanah. Hal ini menimbulkan tingginya erosi, lajunya aliran permukaan, hilangnya hara dalam tanah, pencemaran oleh zat toksik dalam tanah, serta timbulnya pencemaran tanah dan lingkungan akibat perlakuan yang tidak baik kepada tanah yang dilakukan oleh manusia.

Penyebaran lahan kritis banyak terjadi di wilayah Daerah Aliran Sungai (DAS) di Gorontalo. Salah satu penyebarannya terdapat di DAS Randangan Kabupaten. Data yang ditunjukkan oleh BP-DAS Bone Bolango (2009), bahwa kekritisan DAS di Gorontalo luasnya mencapai 693.801 Ha. Dikawasan DAS Randangan sendiri terdapat $91.494 \mathrm{Ha}$ $(13,19 \%)$ luas lahan kritis, yang terdiri dari $18.832 \mathrm{Ha}(20,58 \%)$ terdapat di luar kawasan hutan, dan $72.662 \mathrm{Ha}(79,42 \%)$ berada di dalam kawasan hutan.

Langkah tatis yang dapat dilakukan dalam merekondisi kembali lahan-lahan pertanian yang telah kritis adalah dengan merehabilitasi lahan yang telah kritis tersebut. Rehabilitasi lahan merupakan suatu kegiatan untuk memulihkan kembali kondisi lahan dengan perlakuan-perlakuan konservasi. Salah satunya adalah dengan melakukan penanaman tanaman tahunan pada lahan yang telah kritis. Pertanyaannya adalah: "Mengapa hal ini dilakukan?". Menyikapi hal tersebut perlu kiranya mengutarakan apa yang menjadi tujuan pokok rehabilitasi lahan tersebut. Dalam Peraturan Presiden Republik Indonesia Tahun 2007, tentang Gerakan Nasional Rehabilitasi Hutan dan Lahan (GNRHL), Editor: Siti Herlinda et. al.

ISBN : 978-979-587-748-6 
bahwa rehabilitasi hutan dan lahan adalah upaya untuk memulihkan, mempertahankan dan meningkatkan fungsi hutan dan lahan sehingga daya dukung, produktivitas dan peranannya dalam mendukung sistem penyangga kehidupan tetap terjaga. Tujuannya ialah mempercepat upaya untuk memulihkan, mempertahankan, dan meningkatkan fungsi hutan dan lahan. Dengan demikian bahwa menjadi tanggungjawab bersama dalam memulihkan dan menjaga lahan agar tetap optimal dalam upaya menyangga kehidupan masyarakat.

Upaya rehabilitasi lahan kritis telah banyak dilakukan baik oleh masyarakat, pemerhati lingkungan, pemerintah, dan stakeholder terkait yang mendambakan keseimbangan lingkungan dan alam ini. Namun, hal mendasar yang menjadi kunci sukses rehabilitasi lahan adalah partisipasi masyarakat itu sendiri sebagai subjek dari segala bentuk kegiatan yang dilakukan. Suparwata (2016), mengatakan bahwa partsipasi masyarakat dalam rehabilitasi lahan kritis merupakan keterlibatan dan keikutsertaan masyarakat dalam segala kegiatan/program yang dicanangkan dimulai dari perencanaan program, realisasi, pemantauan dan pendampingan hingga evaluasi program. Olehnya keberhasilan rehabilitasi lahan sangat ditentukan oleh partisipasi masyarakat yang terlibat langsung pada pengelolaan lahan-lahan yang telah kritis.

Berdasarkan beberapa hal tersebut maka tujuan penelitian ini mengkaji tingkat partisipasi masyarakat dalam pengelolaan rehabilitasi lahan kritis di DAS Randangan Kabupaten Pohuwato.

\section{BAHAN DAN METODE}

\section{Desain Penelitan.}

Desain penelitian ini menggunakan pendekatan survei. Menurut Morissan (2014), bahwa penelitian yang berupaya menjelaskan atau mencatat kondisi atau sikap untuk menjelaskan apa yang ada saat ini. Masyhuri dan Zainuddin (2009), menambahkan dengan survei akan diperoleh fakta-fakta dan keterangan secara faktual baik sosial, ekonomi tentang suatu kelompok/daerah. Oleh karena itu, survei yang dimaksudkan dalam penelitian ini yaitu mengumpulkan data-data tentang kondisi partisipasi masyarakat pada program rehabilitasi lahan kritis di DAS Randangan.

\section{Waktu dan Lokasi Penelitian.}

Penelitian ini dilakukan di DAS Randangan, Kabupaten Pohuwato, Provinsi Gorontalo. Lokasi tersebut merupakan eks-lokasi kegiatan rehabilitasi lahan kritis sejak tahun 2010. Lokasi ditentukan secara sengaja, dengan pertimbangan: (a) sebaran lahan kritis di DAS Randangan cukup luas baik yang berada di luar maupun di dalam kawasan hutan, dan (b) kerusakan sungai randangan yang semakin mengkawatirkan terlihat oleh banyak sedimen yang terkumpul dibir sungai. Penelitian ini dilaksanakan dari Bulan April sampai Juli 2017.

\section{Populasi dan Teknik Penarikan Sampel.}

Populasi adalah masyarakat perehabilitasi lahan kritis di DAS Randangan, berjumlah 150 orang. Sampel penelitian ini dihitung dengan menggunakan rumus Taro Yamane dalam Riduwan (2013) dengan tingkat presisi 10\% dari total populasi, yaitu:

$$
n=\frac{N}{N \cdot d^{2}+1} \quad \text { Dimana }: \begin{aligned}
& \mathrm{n}=\text { Jumlah sampel } \\
& \mathrm{N}=\text { Jumlah populasi } \\
& \mathrm{d}^{2}=\text { Presisi yang ditetapkan }
\end{aligned}
$$

Editor: Siti Herlinda et. al. ISBN : 978-979-587-748-6 


$$
n=\frac{150}{\left(150 \cdot 0 \cdot 1^{2}\right)+1}=60 \text { Responden }
$$

Selanjutnya sampel ditentukan secara proporsional random sampling memakai rumus alokasi proportional (Tabel 1), dengan rumus (Sugiyono, 2014):

$$
n i=\frac{N i}{N} \cdot n \quad \begin{aligned}
\text { Dimana }: \mathrm{ni} & =\text { Jumlah Sampel menurut Stratum } \\
\mathrm{n} & =\text { Jumlah Sampel Seluruhnya } \\
\mathrm{Ni} & =\text { Jumlah Populasi menurut Stratum }
\end{aligned}
$$

Tabel 1. Populasi dan sampel pada rehabilitasi lahan kritis di DAS Randangan

\begin{tabular}{ccc}
\hline Kecamatan & Populasi & Sampel \\
\hline Taluditi & 30 & 12 \\
Wanggarasi & 75 & 30 \\
Lemito & 30 & 12 \\
Popayato Barat & 15 & 6 \\
\hline Total & $\mathbf{1 5 0}$ & $\mathbf{6 0}$ \\
\hline
\end{tabular}

\section{Teknik Pengumpulan Data.}

Sumber data yakni data primer dan data sekunder. Data primer dikumpulkan berupa pendapat, opini, pandangan terhadap partisipasi pada program rehabilitasi lahan kritis, sedangkan data sekunder berupa data dari BP-DAS bone Bolango, dan data Desa. Teknik pengumpulan data yang dilakukan adalah dengan (1) observasi, melakukan penjajakan lokasi penelitian, sosialisasi dan koordinasi dalam penelitian, (2) wawancara terstruktur, dan kuesioner sebagai alat bantu dalam pengumpulan datanya. Teknik dilakukan untuk memudahkan peneliti dalam pengumpulan data lapangan, dan (3) dokumenter, mendokumentasikan seluruh kegiatan dalam penelitian.

\section{Analisis Data.}

Analisis data dalam penelitian ini yaitu (1) analisis partisipasi masyarakat dan (2) analisis deskriptis.

1. Analisis partisipasi menggunakan ditentukan dengan Skala interval kelas pada masingmasing tingkatan partisipasi (rendah, sedang, tinggi). Penentuan kelas interval dari kategori rendah, sedang dan tinggi tersebut dapat dihitung dengan menggunakan rumus Nasir (2013), yaitu sebagai berikut :

$$
\begin{aligned}
k & =\frac{R}{I} \\
\text { Dimana }: \mathrm{k} & =\text { interval kelas } \\
\mathrm{I} & =\text { jumlah interval kelas } \\
\mathrm{R} & =\text { range }
\end{aligned}
$$

2. Analisis deskripsi digunakan untuk menggambarkan serta mendeskripsikan tingkatan partisipasi masyarakat dari data lapangan yang diperoleh.

\section{HASIL}

Keberhasilan program rehabilitasi lahan kritis salah satunya dapat ditentukan oleh tingkat partisipasi masyarakat yang berada pada kawasan DAS. Partisipasi masyarakat Editor: Siti Herlinda et. al. ISBN : 978-979-587-748-6 
merupakan adanya keikutsertaan pada berbagai kegiatan rehabilitasi lahan kritis baik bidang perencanaan, pelaksanaan dan evaluasi. Sehingga, dalam meminimalisir kerusakan DAS Randangan sangat penting untuk mengetahui tingkat partispasi masyarakat pada pengelolaan rehailitasi lahan kritis.

\section{Tingkat Partisipasi Masyarakat pada Perencanaan Rehabilitasi Lahan Kritis.}

Partisipasi masyarakat merupakan kontrol adanya kekuasaan yang berlebih agar lebih efektif ditujukan sebesar-besarnya untuk masyarakat dalam konsep good governance (Fadil, 2013). Kegiatan perencanaan bertujuan untuk mempersiapkan segala sesuatu secara sistematis supaya hasilnya mampu dijadikan sebagai acuan dalam pelaksanaan kegiatan. Oleh karena itu, pertemuan atau rapat perlu dilakukan untuk menyusun perencanaan sebelum penanaman dilaksanakan. Melalui rapat-rapat perencanaan tersebut diharapkan mampu menghasilkan keputusan secara mufakat berdasarkan aspirasi dari setiap warga (Auliyani et al., 2014). Dimensi perencanaan merupakan tahap awal yang dilakukan dalam upaya pengelolaan lahan kritis. Pada tahap perencanaan beberapa kegiatan yang dilakukan ialah penetuan lokasi rehabilitasi dan penentuan jenis tanaman. Tahap perencanaan akan sangat menentukan keberhasilan tahap pelaksanaan dan evaluasi. Hasil penelitian disajikan pada Tabel 2.

Tabel 2. Partisipasi masyarakat pada perencanaan rehabilitasi lahan kritis

\begin{tabular}{lcccccc}
\hline \multirow{2}{*}{ Bentuk Partisipasi Perencanaan } & \multicolumn{5}{c}{ Kategori Partisipasi } \\
\cline { 2 - 7 } & $1-2$ (rendah) & $(\%)$ & $3-4($ sedang) & $(\%)$ & $>4$ (tinggi) & $(\%)$ \\
\hline Penentuan Lokasi Rehabilitasi & 39 & 65 & 13 & 21.7 & 8 & 13.3 \\
Penentuan Jenis Tanaman & 42 & 70 & 10 & 16.7 & 8 & 13.3 \\
\hline
\end{tabular}

Sumber: Data Primer Diolah, 2017

Hasil penelitian (Tabel 2) menunjukkan bahwa pada kegiatan penentuan lokasi rehabilitasi tingkat partisipasi masyarakat dalam kategori rendah (65\%), sedang $(21.7 \%)$, dan tinggi $(13.3 \%)$. Sedangkan pada kegiatan penentuan jenis tanaman tingkat partisipasi masyarakat pada kategori rendah (70\%), sedang (16.7\%), dan tinggi (13.3\%).

\section{Tingkat Partisipasi Masyarakat Tahap Pelaksanaan Rehabilitasi Lahan Kritis.}

Tahap pelaksanaan rehabilitasi merupakan tahap masyarakat mulai melakukan aksi di lapangan yang berkaitan dengan kegiatan rehabilitasi lahan. Kegiatan pada tahap pelaksanaan rehabilitasi lahan kritis meliputi pemeliharaan bibit tanaman, penentuan pola dan jarak tanam, penanaman bibit tanaman, dan penyulaman tanaman. Hasil penelitian disajikan pada Tabel 3.

Tabel 3. Partisipasi masyarakat pada tahap pelaksanaan rehabilitasi lahan kritis

\begin{tabular}{lcccccc}
\hline \multirow{2}{*}{ Bentuk Partisipasi Pelaksanaan } & \multicolumn{5}{c}{ Kategori Partisipasi } \\
\cline { 2 - 7 } & \multirow{2}{*}{$1-2$ (rendah) } & $(\%)$ & $3-4$ (sedang) & \multirow{2}{*}{$\%$} & $\begin{array}{c}>4 \\
\text { (tinggi) }\end{array}$ & $(\%)$ \\
\hline Memelihara bibit & 19 & 31.7 & 32 & 53.3 & 9 & 15 \\
Penentuan pola dan jarak tanam & 33 & 55 & 20 & 33.3 & 7 & 11.7 \\
Penanaman bibit tanaman & 9 & 15 & 35 & 58.3 & 16 & 26.7 \\
Penyulaman tanaman & 34 & 56.6 & 19 & 31.7 & 7 & 11.7 \\
\hline
\end{tabular}

Sumber: Data Primer Diolah, 2017

Hasil penelitian menunjukkan bahwa tahap pelaksanaan rehabilitasi lahan kritis partisipasi masyarakat tergolong sedang pada pemeliharaan bibit (53.3\%), penanaman bibit

Editor: Siti Herlinda et. al.

ISBN : 978-979-587-748-6 
(58.3\%), tetapi rendah pada penentuan pola dan jarak tanam (55\%), dan penyulaman tanaman $(56.6 \%)$.

\section{Tingkat Partisipasi Masyarakat Tahap Evaluasi Rehabilitasi Lahan Kritis.}

Menurut FAO (1988), bahwa evaluasi partisipasi adalah analisis sistematis dengan manajemen proyek dan anggota kelompok, menetapkan ulang kebijakan/objektivitas, pengaturan ulang institusi, atau pengembangan ulang sumberdaya. Jatmiko et al., (2012), juga mengungkapkan bahwa evaluasi rehabilitasi hutan dan lahan (RHL) yang sudah pernah dilakukan sampai saat ini masih terfokus pada pertanggungjawaban kegiatan, hanya menggunakan ukuran persentase hidup tanaman, tinggi pohon, dan tingkat kesehatan tanaman hasil RHL, yang belum cukup untuk mengevaluasi secara total tingkat keberhasilan RHL sebagai sebuah sistem.

Pada tahap evaluasi rehabilitasi lahan kritis, partisipasi masyarakat sangat diperlukan, apalagi pada tahap evaluasi program rehabilitasi. Sumbangan partisipasi masyarakat pada tahap evaluasi akan menentukan langkah program selanjutnya, seberapa jauh program tersebut telah dilaksanakan dan apa saja yang belum dilaksanakan. Dalam penelitian ini, bentuk partisipasi masyarakat tahap evaluasi rehabilitasi lahan kritis dilihat dari indikator intensif melakukan monitoring pertanaman. Hasil penelitian disajikan pada Tabel 4.

Tabel 4. Partisipasi masyarakat tahap evaluasi rehabilitasi lahan kritis

\begin{tabular}{lcccccc}
\hline \multirow{2}{*}{ Bentuk Partisipasi Evaluasi } & \multicolumn{5}{c}{ Kategori Partisipasi } \\
\cline { 2 - 7 } & $1-2$ (rendah) & $\%$ & $3-4$ (sedang) & $\%$ & $>4$ (tinggi) & $\%$ \\
\hline Monitoring pertanaman & 40 & 66.7 & 14 & 23.3 & 6 & 10 \\
\hline
\end{tabular}

Hasil penelitian (Tabel 4), menujukkan bahwa partisipasi masyarakat untuk ikut serta dalam melakukan monitoring pertanaman berada pada kategori rendah $(66.7 \%$ masyarakat tidak berpartisipasi).

\section{PEMBAHASAN}

Lahan kritis merupakan lahan yang telah mengalami kerusakan sehingga kehilangan atau berkurang fungsi sesuai peruntukannya (Didu, 2001). Akibat adanya pemanfaatan sumberdaya alam yang melebihi daya dukung lingkungan dan tidak dibarengi dengan usaha konservasi tanah dan air, ternyata telah menimbulkan munculnya ketidakseimbangan lingkungan yaitu terus bertambahnya luas lahan kritis (Nugroho, 2000). Menyadari hal demikian, bahwa masalah DAS bukan hanya bertumpu pada pada masalah fisik dan teknis saja, maka perlu adanya suatu keseimbangan dengan pengelolan DAS yang bersifat partisipatoris. Pendekatan pembangunan partisipatoris dimulai dengan orang-orang yang paling mengetahui tentang sistem kehidupan masyarakat, setempat yaitu masyarakat itu sendiri (Brooks et al., 1989 dalam Nugroho, 2003).

Pengelolaan lahan kritis dewasa ini hendaknya lebih mengarah pada pengaktipan kembali partisipasi masyarakat yang berada di kawasan DAS, baik pada tahap perencanaan, pelaksanaan dan evaluasi. Tingkat partisipasi masyarakat dalam pengelolaan lahan kritis akan menentukan keberhasilan rehabilitasi yang dilakukan.

Pada tahap perencanaan rehabilitasi lahan kritis, bahwa tingkat partisipasi masyarakat pada tergolong rendah, sebab $65 \%$ masyarakat tidak ikut berpartisipasi pada penentuan lokasi rehabilitasi lahan kritis, dan $70 \%$ masyarakat tidak berpartisipasi pada penentuan jenis tanaman (Tabel 2). Rendahnya tingkat partisipasi ini diakibatkan pada

Editor: Siti Herlinda et. al.

ISBN : 978-979-587-748-6 
dimensi perencanaan tidak secara keseluruhan anggota kelompok tani dilibatkan. Sehingga Nuddin et al., (2007), mengungkapkan bahwa perencanaan akan efektif jika disusun melalui koordinasi dengan melibatkan semua stakehoders. Tetapi jika yang terjadi sebaliknya, maka penerapan fungsi managemen akan terhambat yang berujung pada kegagalaan program. Beberapa hasil penelitian seperti yang dilaporkan oleh Sandyatma dan Hariadi (2012), bahwa tingkat partisipasi ditingkat perencanaan tergolong rendah dengan nilai $27.33 \%$ dari total nilai partisipasi. Selanjutnya Ansori (2012), juga melaporkan tingkat partisipasi masyarakat pada tahap perencanaan tergolong rendah karena $61.1 \%$ mengatakan tidak ikut perencanaan.

Rendahnya pengelolaan rehabilitasi lahan kritis tahap perencanaan disebabkan oleh rendahnya tingkat penyuluhan, sosialisasi dan pendampingan yang diikuti oleh masyarakat perehabilitasi lahan kritis. Disamping itu, tingkat pendidikan juga sangat menentukan masyarakat dalam pengelolaan lahan kritis tahap perencanaan. Seperti yang diungkapkan oleh Ansori (2012), bahwa faktor rendahnya pendidikan dari para petani sangat berpengaruh terhadap kemampuannya dalam membuat perencanaan. Dalam rapat kelompok tani kebanyakan petani hanya diam tidak banyak usul, lebih sering menjadi peserta pasif dan menyetujui apa yang disampaikan ketua kelompok. Petani terbiasa diperintah oleh mandor pada saat menggarap lahan, dan mengikut saja apa yang diinstruksikan. Rendahnya pengetahuan tentang pengelolaan hutan juga berpengaruh terhadap partisipasi petani. Pada tahap pelaksanaan rehabilitasi lahan kritis, bahwa masyarakat pada pelaksanaan rehabilitasi lahan kritis telah memiliki kesadaran lebih tinggi dibandingkan dengan tahap perencanaan. Tingkat partisipasi masyarakat tergolong sedang pada pemeliharaan bibit dan penanaman bibit, tetapi rendah pada penentuan pola dan jarak tanam serta rendah pada kegiatan penyulaman tanaman (Tabel 3). Adanya partisipasi masyarakat pada pelaksanaan kegiatan akan memberikan dampak yang positif terhadap perbaikan lahan kritis. Pada tahap ini masyarakat mulai menganalisis akan hasil yang akan diperolehnya sehingga mau melakukan kegiatan rehabilitasi. Sehingga dimensi kegatan dalam pelaksanaan lebih tinggi dengan perencanaan.

Hal senada juga disampaikan oleh Dewi (2013), bahwa tingkat partisipasi masyarakat pada tahap pelaksanaan berada pada level tertinggi dibandingkan tingkat partisipasi masyarakat pada tahap perencanaan dan evaluasi. Hal ini menunjukkan bahwa setelah mendapatkan sosialisasi pada tahap perencanaan, masyarakat dengan kesadaran sendiri dan tanpa paksaan dari pihak manapun ikut serta dalam pelaksanaan kegiatan. Dilaporkan juga oleh Dipokusumo (2011) bahwa dalam implementasi sebagian besar berada pada posisi aktif (64.5\%). Pudjianto (2009), bahwa tingkat partisipasi masyarakat pada tahap pelaksanaan secara umum tergolong sedang (46.8\%). Pada tahap ini masyarakat sudah mulai diajak konsultasi dalam pelaksanaan kegiatan, dimasukkan menjadi anggota dalam badan-badan kerja dan berbagi tanggung jawab dalam pelaksanaan kegiatan meskipun seringkali suara mereka tidak diperhitungkan karena kemampuan dan kedudukannya relatif rendah.. Pada tahap evaluasi rehabilitasi lahan kritis tingkat partisipasi masyarakat tergolong rendah (Tabel 4). Hal ini mengindikasikan rendahnya keikutsertaan masyarakat dalam setisp kegiatan evaluasi. Menurut pandangan masyarakat yang tergabung dalam anggota kelompok tani perehabilitasi, bahwa pada kegiatan evaluasi tidak secara keseluruhan petani dilibatkan dalam melakukan evaluasi. Namun hanya sebagian kecil saja yang ditugaskan melakukan monitoring seperti ketua kelompok, sekretaris dan bendahara kelompok. Sehingga sebagian besar anggota kelompok tersebut tidak mengetahui secara pasti terhadap evaluasi pada kegiatan rehabilitasi lahan kritis. Seperti yang dilaporkan oleh Muis (2007), menunjukkan tingkat partisipasi peserta pada kegiatan GN-RHL menyatakan bahwa tidak pernah terlibat pada item kegiatan evaluasi.

Editor: Siti Herlinda et. al.

ISBN : 978-979-587-748-6 
Selanjutnya Suparwata et al., (2017), mengatakan hanya $71.7 \%$ masyarakat tidak berpartisipasi pada tahap evaluasi dalam kegiatan rehabilitasi lahan kritis. Demikian juga oleh Sandyatma dan Hariadi (2012), bahwa tingkat keterlibatan anggota Gapoktan pada tahap pemantauan dan evaluasi hanya mencapai $25.17 \%$.

Partisipasi pada rehabilitasi (baik tahap perencanaan, pelaksanaan, dan evaluasi) sangat dibutuhkan untuk menjaga keberlanjutan lahan-lahan pertanian. Bila tidak ada kesadaran dari masyarakat di kawasan DAS maka niscaya sumberdaya DAS akan semakin rusak, dan perluasan lahan kritis akan semakin cepat. Menindaklanjuti hal tersebut, maka diperlukan kerjasama dari berbagai pihak untuk bersama-sama mengelola, menjaga, dan melestarikan lahan kritis di kawasan DAS. Sehingga dibutuhkan perencanaan yang matang terhadap pengelolaan lahan di kawasan DAS. Pelaksanaan yang sesuai dengan tahapantahapan kegiatan berdasarkan standar operasionalnya, serta evaluasi yang dibutuhkan dengan melibatkan seluruh masyarakat dan komponen yang memiliki kepentingan di dalamnya. Sehingga dibutuhkan pengelolaan lahan kritis secara berkelanjutan.

Pembangunan yang berkelanjutan hanya akan tercapai apabila kebutuhan manusia dan potensi sumber daya alam yang dimiliki memenuhi kebutuhan manusia, seimbang seiring dengan waktu. Pengelolaan dan pengembangan SDA diarahkan untuk mempertahankan keberadaan dan keseimbangan yang dinamis melalui berbagai usaha perlindungan, rehabilitasi dan pemeliharaannya (Raka et al., 2014). Pengelolaan rehabilitasi lahan berkelanjutan hendaknya dapat meningkatkan produksi tanaman yang diperoleh sehingga dapat meningkatkan ekonomi masyarakat itu sendiri.

Pembangunan ekonomi yang baik tidak hanya mementingkan satu aspek saja tetapi semua aspek juga dipertimbangkan. Seperti keseimbangan antara aspek lingkungan, social dan ekonomi. Ketiga aspek ini bila dilakukan secara bersama-sama maka akan berdampak pada semakin baiknya pengelolaan sumberdaya alam seperti lahan pertanian.

Dalam hal ini Jaya (2004), mengungkapkan bahwa pembangunan ekonomi yang berbasis sumberdaya alam yang tidak memperhatikan aspek kelestarian lingkungan pada akhirnya akan berdampak negatif pada lingkungan itu sendiri, karena pada dasarnya sumberdaya alam dan lingkungan memiliki kapasitas daya dukung yang terbatas. Dengan kata lain, pembangunan ekonomi yang tidak memperhatikan kapasitas sumberdaya alam dan lingkungan akan menyebabkan permasalahan pembangunan dikemudian hari. Adibroto (2002), maka dirasakan perlu untuk melakukannya melalui suatu pendekatan Pengelolaan DAS yang Berkelanjutan.

\section{KESIMPULAN}

Dari hasil penelitian dapat disimpulkan bahwa pada perencanaan tingkat partisipasi masyarakat rendah pada penentuan lokasi rehabilitasi (65\%), dan penentuan jenis tanaman (70\%). Pada pelaksanaan tergolong sedang pada pemeliharaan bibit $(53.3 \%)$, penanaman bibit (58.3\%), tetapi rendah pada penentuan pola dan jarak tanam (55\%), dan penyulaman tanaman (56.6\%). Tahap evaluasi tergolong rendah untuk melakukan monitoring pertanaman $(66.7 \%)$. Hal ini mengindikasikan bahwa masih minimnya tingkat kesadaran masyarakat, olehnya dibutuhkan gerakan konkrit untuk pengelolaan lahan kritis.

\section{UCAPAN TERIMA KASIH}

Melalui kesempatan ini penulis mengucapkan terima kasih banyak pada masyarakat yang berada di DAS Randangan yang telah menerima dan memberikan informasi konkrit kepada peneliti.

Editor: Siti Herlinda et. al.

ISBN : 978-979-587-748-6 


\section{DAFTAR PUSTAKA}

Adibroto, T.A. 2002. Pengembangan Teknologi Lingkungan dalam Pengelolaan DAS yang Berkelanjutan. Jurnal Teknologi Lingkungan, 3(1): 33-42.

Arifin, B. 2013. Ekonomi Pembangunan Pertanian. Bogor: IPB Press.

Arsyad, M. 2012. Membangun Pertanian dan Perdesaan untuk Percepatan Reduksi Kemiskinan. Cetakan I, hlm: 189-199. Dalam: Gagasan, Pemikiran, dan Harapan Alumni Fakultas Pertanian UNHAS terhadap Pembangunan Pertanian Indonesia. Makassar: Identitas Universitas Hasanuddin.

Balai Pengelolaan Daerah Aliran Sungai (BP-DAS) Bone Bolango. 2009. Statistik Pembangunan Balai Pengelolaan Daerah Aliran Sungai Bone Bolango. Gorontalo: Departemen Kehutanan, Direktorat Jenderal Rehabilitasi Lahan dan Perhutanan Sosial.

Dahlan, D. 2012. Kemiskinan dan Pemberdayaan Petani. Cetakan I, hlm: 169-174. Dalam: Gagasan, Pemikiran, dan Harapan Alumni Fakultas Pertanian UNHAS terhadap Pembangunan Pertanian Indonesia. Makassar: Identitas Universitas Hasanuddin.

Didu, M.S. 2001. Analisis Posisi dan Peran Lembaga Serta Kebijakan dalam Proses Pembentukan Lahan Kritis. Jurnal Teknologi Lingkungan, 2(1): 93-105.

FAO. 1988. Participatory Monitoring and Evaluation (Handbook for Training Field Workers). Bangkok: Rapa Publication.

Jatmiko, A., Sadono, R., dan Faida, L.R.W. 2012. Evaluasi Kegiatan Rehabilitasi Hutan Dan Lahan Menggunakan Analisis Multikriteria (Studi Kasus Di Desa Butuh Kidul Kecamatan Kalikajar Kabupaten Wonosobo, Jawa Tengah). Jurnal Ilmu Kehutanan, 6(1): 30-44.

Jaya, A. 2004. Konsep Pembangunan Berkelanjutan (Sustainable Development). Makalah Ilmiah. Program S3, Institut Pertanian Bogor. Bogor. http://file.upi.edu/Direktori/FIP/JUR._PEND._LUAR_SEKOLAH/1952072519780 31-ACE_SURYADI/askar_jaya.pdf (Diakses, 29 November 2015).

Masyhuri \& Zainuddin, M. 2009. Metodologi Penelitian (Pendekatan Praktis dan Aplikatif). Bandung: PT. Refika Aditama.

Morissan. 2014. Metode Penelitian Survei. Cetakan Ke-2. Jakarta: Kencana Prenadamedia Group.

Muis, H. 2007. Pengembangan Partisipasi Masyarakat dalam Gerakan Nasional Rehabilitasi Hutan dan Lahan (GN-RHL) : (Kasus di Kelurahan Layana Kecamatan Palu Timur dan Kelurahan Lambara Kecamatan Palu Utara Kotamadya Palu, Sulawesi Tengah). [Disertasi]. Bogor: Institut Pertanian Bogor.

Nasir, M. 2013. Metode Penelitian. Cetakan Ke-VIII. Bogor: Ghalia Indonesia.

Nuddin, A., Sinukaban, N., Murtilaksono, K., dan Alikodra, H.S. 2007. Analisis Sistem Kelembagaan dalam Perencanaan dan Strategi Pengelolaan Lahan Kritis DAS Bila. Jurnal Penyuluhan, 3(2): 119-128.

Nugroho, S.P. 2000. Minimalisasi Lahan Kritis melalui Pengelolaan Sumberdaya Lahan dan Konservasi Tanah dan Air Secara Terpadu. Jurnal Teknologi Lingkungan, 1(1): 73-82.

Nugroho, S.P. 2003. Pergeseran Kebijakan dan Paradigma Baru dalam Pengelolaan Daerah Aliran Sungai di Indonesia. J.Tek.Ling. P3TL-BPPT, 4(3): 136-142.

Nuhung, I.A. 2012. Kemiskinan, Akar dan Solusi Terapinya. Cetakan I, hlm: 175-188. Dalam: Gagasan, Pemikiran, dan Harapan Alumni Fakultas Pertanian UNHAS terhadap Pembangunan Pertanian Indonesia. Makassar: Identitas Universitas Hasanuddin.

Editor: Siti Herlinda et. al.

ISBN : 978-979-587-748-6 
Raka, I.D.N., Sucika, P.N., Nada, I.M., Wiswasta, I.G.N.A., Widnyana, I.K. 2014. Model Penanggulangan Erosi dan Pengelolaan Daerah Aliran Sungai (DAS) dalam Upaya Konservasi Tanah dan Rehabilitasi Lahan Kritis di Bali. Artikel. Fakultas Pertanian UNMAS, Denpasar. http://lppm.unmas.ac.id/wp-content/uploads/2014/06/64-DWRAKA-UNMASAR1.pdf (Diakses, 9 Februari 2015).

Riduwan. 2013. Metode dan Teknik Menyusun Tesis. Cetakan Ke-IX. Bandung: Penerbit Alfabeta.

Sandyatma, Y.H., \& Hariadi, S.M. 2012. Partisipasi Anggota Kelompok Tani dalam Menunjang Efektivitas Gapoktan pada Kegiatan Penguatan Lembaga Distribusi Pangan Masyarakat di Kabupaten Bogor. Jurnal Kawistara, 2(3): 225-328.

Sugiyono. 2014. Metode Penelitian Kombinasi (Mixed Methods). Bandung: Alfabeta.

Suparwata, D.O. 2016. An Analysis of Public Participation on Critical Land, in Randangan Watershed, Pohuwato Regency. [Tesis]. Program Pascasarjana, Universitas Hassanuddin. Makassar.

Suparwata, D.O., M. Arsyad, M.S. Hamidun, D. Rukmana, M.I. Bahua. 2016. Community Participation on Evaluation Stage in Critical Land Rehabilitation Program. Advances in Environmental Biology, 10(10): 170-180.

Editor: Siti Herlinda et. al. ISBN : 978-979-587-748-6 